\title{
AIRBORNE UV LIDAR FOR FOREST PARAMETER RETRIEVALS
}

\author{
Xiaoxia Shang*, Patrick Chazette, and Julien Totems \\ Laboratoire des Sciences du Climat et de l'Environnement, CEA-CNRS-UVSQ, 91191 Gif-sur-Yvette \\ Cedex, France, *Email: xiaoxia.shang@gmail.com
}

\begin{abstract}
A full-waveform UV lidar performed airborne measurements over several temperate and tropical forests sites. The structural and ecological parameters (canopy height, quadratic mean canopy height and apparent foliage) were extracted from lidar backscattered profiles. The aboveground carbon and leaf area index are also evaluated from lidar measurements.
\end{abstract}

\section{INTRODUCTION}

Representing $80 \%$ of the continental biospheric carbon, forests play a crucial role in Earth's carbon cycle by absorbing carbon dioxide from the atmosphere and storing it into biomass. They are also important sources and sinks for several atmospheric chemical species (e.g. volatile organic compounds, ozone). Both energy and chemical component fluxes between the low troposphere and the biosphere remains however largely unknown. What is clear is that it crucially depends on forest properties such as living biomass, composition and spatial structure. Measuring the three-dimensional vegetation structure of forests is thus essential to address this issue, as such structure contains a substantial amount of information about the state of development of plant communities and their potential to interact with the low troposphere. Active remote sensing instruments, including lidar and radar, can peer through the forest canopy down to the ground level. In particular, a dedicated lidar can provide a full description of the forest vertical structure (including canopy top, tree crown base height and understory structures) [1][2]. A full-waveform lidar with a large footprint can reliably extract the vertical structure of an optically thick tropical rainforest [3].

\section{METHODOLOGY}

The full-waveform UV lidar ULICE (Ultraviolet LIdar for Canopy Experiment), developed in our laboratory as a spaceborne demonstrator, performed airborne measurements over varied temperate and tropical forest biomes. Its main characteristics are given in Table 1 . The use of UV spectral domain $(355 \mathrm{~nm})$ leads to a significant reduction of the multiple scattering effects, compared to near infrared wavelengths, in the forest structures. Depending on the sampled site, ULICE has 2 operation modes: the classic mode for temperate forests, and tropical mode for tropical forest. Their footprints diameters at the ground are $\sim 2 \mathrm{~m}$ or $\sim 10 \mathrm{~m}$, respectively, for a flight altitude of $\sim 300 \mathrm{~m}$ above the ground level.

The lidar system was embedded on an Ultra-Light Aircraft (ULA) as shown in Figure 1. It is coupled with an ancillary instrument which provides the position and the attitude information of the ULA to derive the angle between the lidar line of sight and the nadir direction. The principle of the canopy lidar measurement is shown in Figure 2, along with a schematic lidar backscattered profile showing forest vertical structures.

Table 1. Main characteristics of ULICE (Ultraviolet LIdar for Canopy Experiment).

\begin{tabular}{|c|c|c|}
\hline & \multirow{2}{*}{ Characteristics } & ULICE \\
\hline & & classic tropical \\
\hline \multirow[t]{6}{*}{ Emitter } & Wavelength & $355 \mathrm{~nm}$ \\
\hline & Mean energy per pulse & $\sim 7 \mathrm{~mJ}$ \\
\hline & Pulse duration & $\sim 6 \mathrm{~ns}$ \\
\hline & $\begin{array}{l}\text { Pulse repetition } \\
\text { frequency }\end{array}$ & $1-100 \mathrm{~Hz}$ \\
\hline & Beam diameter & $20 \mathrm{~mm}$ \\
\hline & $\begin{array}{c}\text { Maximum beam } \\
\text { divergence }\end{array}$ & $9 \mathrm{mrad}$ \\
\hline \multirow[t]{6}{*}{ Receiver } & Reception diameter & $150 \mathrm{~mm}$ \\
\hline & $\begin{array}{l}\text { Reception optical } \\
\text { density }\end{array}$ & adjustable \\
\hline & Filter bandwidth & $0.3 \mathrm{~nm}$ \\
\hline & Total field of view & $33 \mathrm{mrad}$ \\
\hline & Detector & \multirow{2}{*}{$\begin{array}{l}\text { Photomultiplicateur } \\
\text { Analog }\end{array}$} \\
\hline & Detection mode & \\
\hline Acquisition & Sampling frequency & $100-500 \mathrm{MHz}$ \\
\hline \multirow{3}{*}{ Global } & $\begin{array}{l}\text { Weight of the optical } \\
\text { head }\end{array}$ & $\sim 20 \mathrm{~kg}$ \\
\hline & $\begin{array}{l}\text { Weight of the } \\
\text { electronics }\end{array}$ & $\sim 15 \mathrm{~kg}$ \\
\hline & $\begin{array}{c}\text { Electric supply } \\
(2 \times 12 \mathrm{~V} \text { batteries })\end{array}$ & $24 \mathrm{~V} / \sim 400 \mathrm{~W}$ \\
\hline
\end{tabular}




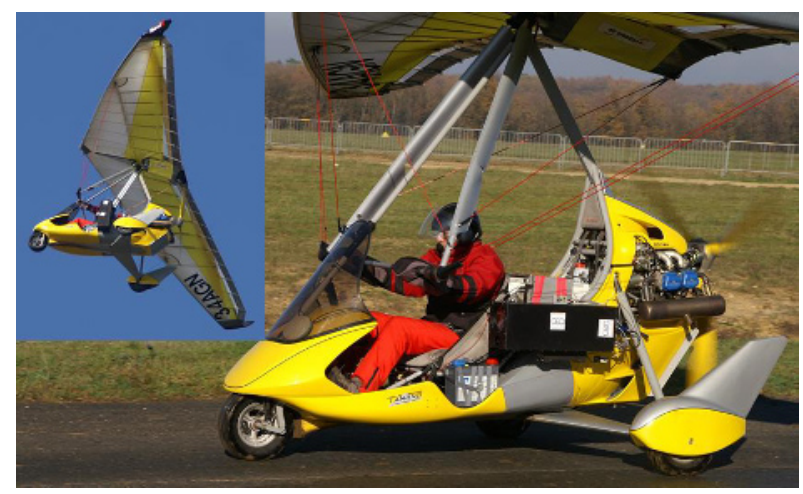

Figure 1. Photo of ULICE onboard ULA.

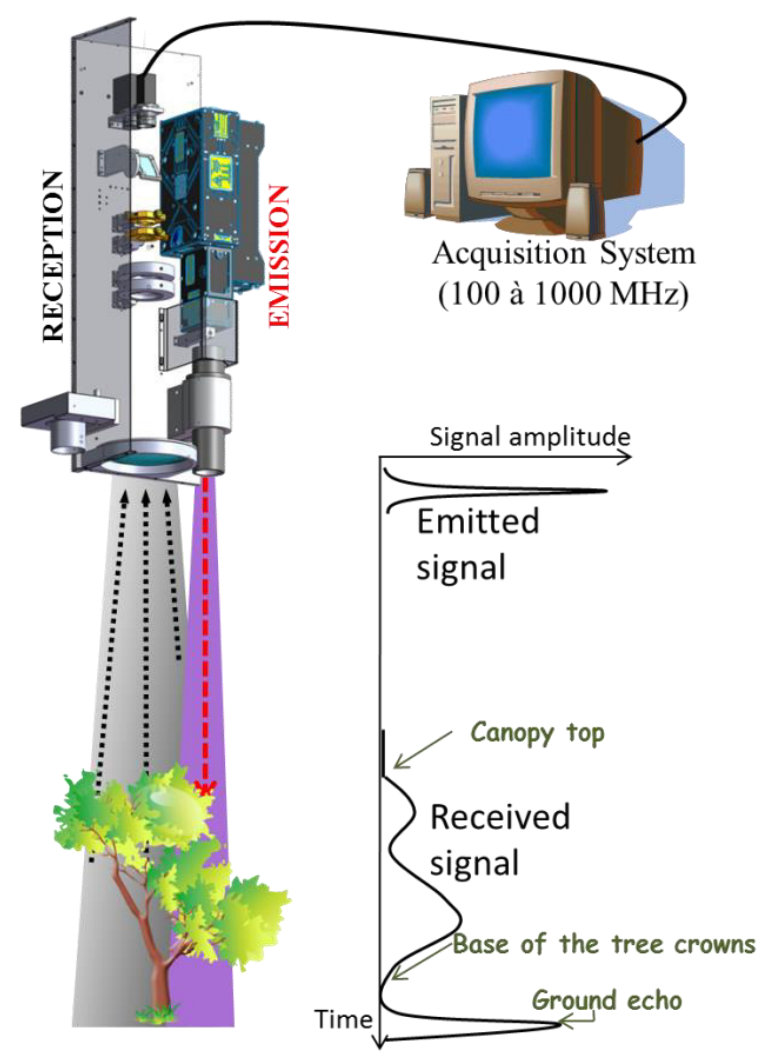

Figure 2. Principle of the canopy lidar measurement.

\section{RESULTS}

In order to characterize the forest biomes, the structural and ecological parameters are studied, such as the canopy height $(\mathrm{CH})$, the aboveground carbon (AGC), and the leaf area index (LAI). Here we present some results for our sampling sites.

\subsection{Structural parameters}

Lidar backscatter profiles include a signature from vertical forest structures, which is dominant compared to the atmospheric contribution. Hence, the canopy height $(\mathrm{CH})$ can be extracted as the distance between the first return at the upper surface of the vegetation and the last return at the ground surface, with a mean uncertainty of $\sim 1.5 \mathrm{~m}$. An example of lidar-derived $\mathrm{CH}$ is given in Figure 3. The vertical structure within the canopy is also important for forest studies, and can be extracted from lidar backscatter profiles as shown in Figure 4 for a tropical forest in the Réunion Island. The weighted height - quadratic mean canopy height (QMCH) - was used to evaluate the aboveground carbon by several authors [1][4][5], via the relationship found between the QMCH and the AGC as shown in Figure 5.

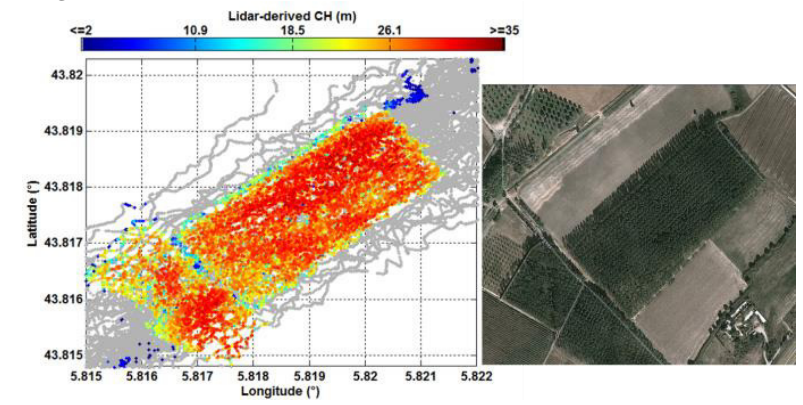

Figure 3. Canopy height $(\mathrm{CH})$ of a plantation of poplar (the footprint diameter at the ground was $\sim 2 \mathrm{~m}$ ). The satellite view (Google Earth ${ }^{\mathrm{TM}}$ ) of sampled site is on the right. 


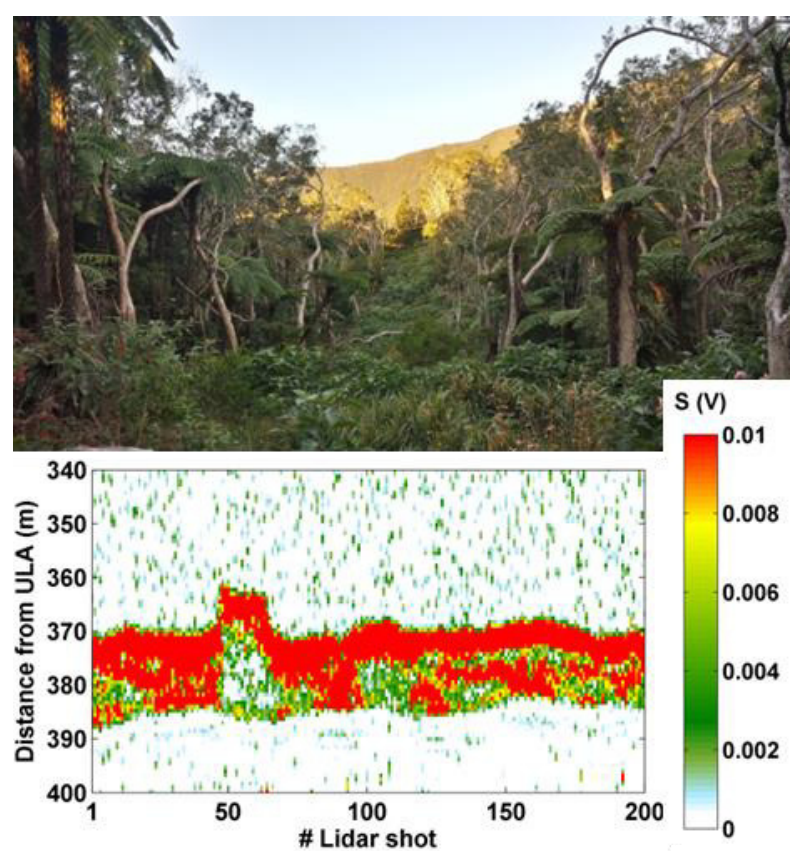

Figure 4. Upper panel: Photo of the sampled tropical forest. Bottom panel: Example of lidar signals over the tropical forest (the footprint at the ground was $\sim 10 \mathrm{~m}$ ).

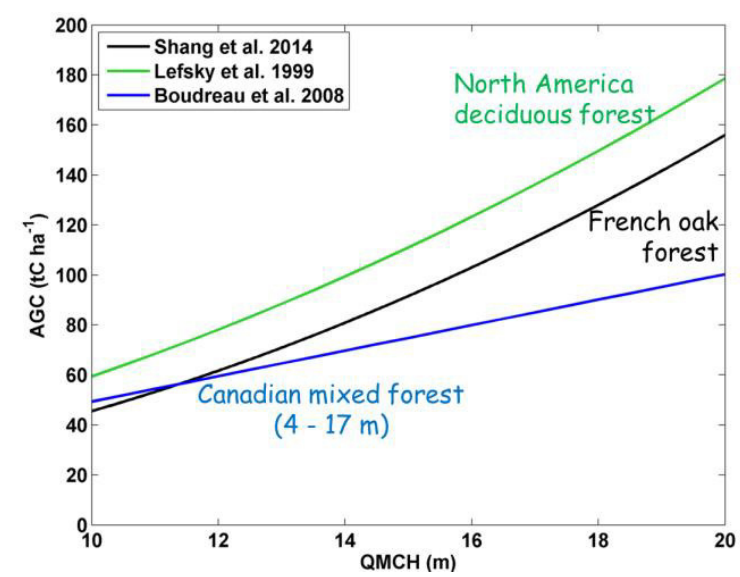

Figure 5. The relationships between $\mathrm{QMCH}$ and AGC published.

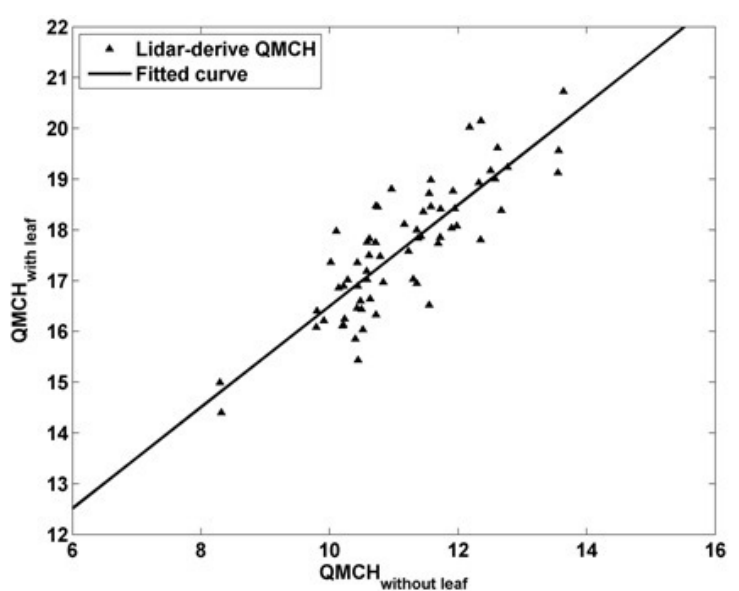

Figure 6. Comparison among the plot-level QMCHs, which are derived from experiments in summer (with leaf) and winter (without leaf). The relationship is found to be $Q M C H_{\text {with leaf }}=0.996 \times Q M C H_{\text {without leaf }}+$ $6.5\left(r^{2} \sim 0.7\right)$.

The effect of leaves on the AGC estimation was studied. By comparing the summer and winter lidar measurements for the same temperate forest site, we found that the different canopy structures imply a significant difference of the QMCH with a mean value $\sim 6 \mathrm{~m}$ (Figure 6 ), which would lead to an AGC overestimation of $\sim 50 \%$ in summer when using a calibration done in winter. This overestimation could be considered as a systematic bias and be corrected.

\subsection{Ecological parameters}

Lidar is also a powerful instrument to retrieve the leaf area index (LAI) [3] using the vertical profile of apparent foliage which informs on both the canopy density and the vertical distribution of leaf biomass along the profile. The lidar-derived forest optical thickness (FOT), depending on the canopy extinction coefficient, was found to get a linear relationship with the mean LAI derived from MODIS over a larger sample site of pin forest as shown in Figure 7. The lidar-derived LAI index seems to overestimate the LAI, because our lidar sampled only the forest area whereas the MODIS production integrated both forest and non-forest area for each considered pixel of $1 \mathrm{~km} \times 1 \mathrm{~km}$. 


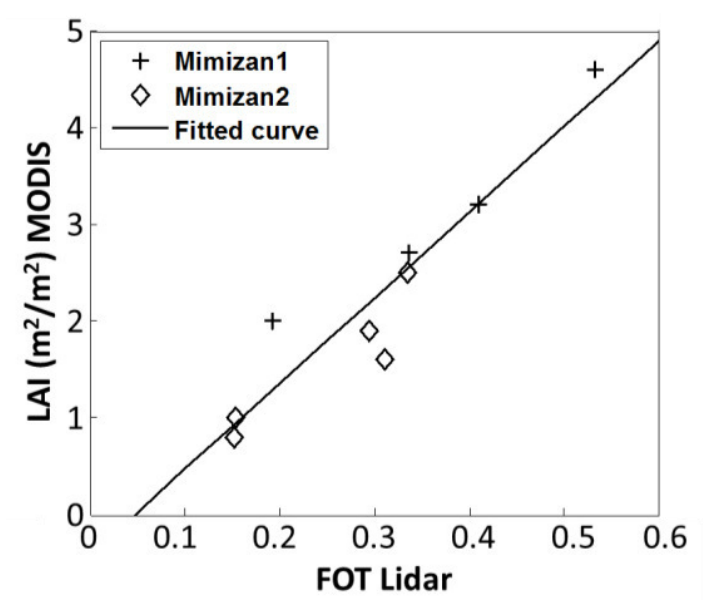

Figure 7. Comparison between FOT computed from lidar measurements and LAI estimated via MODIS for 9 pixels of $1 \mathrm{~km} \times 1 \mathrm{~km}$ in a pin forest.

\subsection{Application to forest type classification}

Using the average values and variability of both $\mathrm{CH}$ and LAI, 7 tropical forest sites of the Réunion Island were classified.
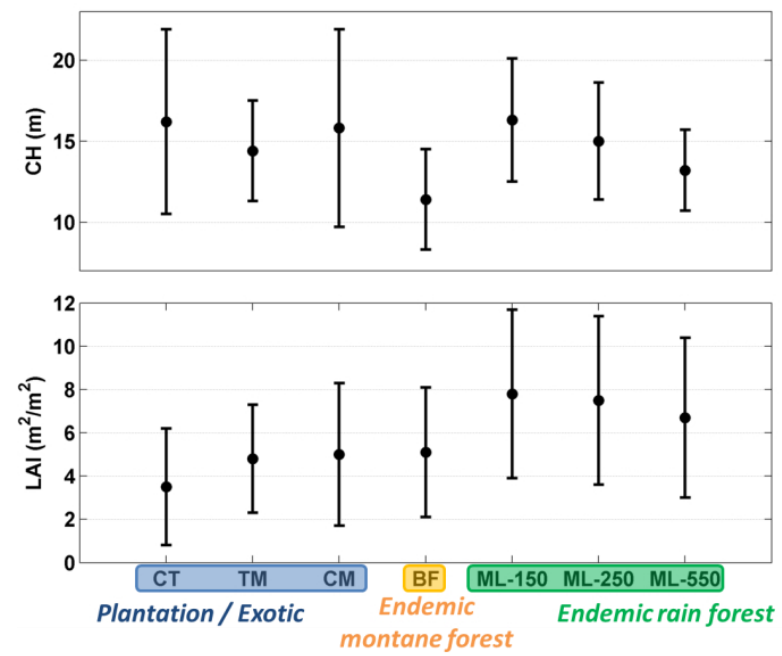

Figure 8. Mean (dot) and standard deviations (line segments) of canopy height and leaf area index for 7 tropical forest site: coastal (CT), Tamarind (TM), Cryptomeria (CM), Bélouve (BF), and Mare-Longue (ML-150, 250 and 550) sites. Measurements with $\mathrm{CH}<$ $5 \mathrm{~m}$ are not considered.

These tropical forests range from coastal to rain forest, including montane cloud forest. As shown in Figure 8 we can identify 2 groups: the endemic (montane/rain) forests and the planted/exotic forests.

\section{CONCLUSIONS}

Airborne lidar measurements were performed over several temperate and tropical forests sites, which allowed building a representative database of lidar vertical profiles. We extracted the structural and ecological parameters (canopy height, quadratic mean canopy height and apparent foliage) from lidar backscattered signal, and then evaluate the aboveground carbon and leaf area index. Even though UV lidar is not a good candidate for spaceborne missions due to the weak atmospheric transmission and the strong absorption by the vegetation in the UV domain, we confirm that the UV wavelength is a good candidate for airborne lidar measurements, and can be a very interesting reference for a spaceborne mission dedicated to forest studies at the global scale.

\section{ACKNOWLEDGMENTS}

The experiments have been funded by the Centre National d'Etudes Spatiales (CNES), the Commissariat à l'Energie Atomique et aux Energies Alternatives (CEA), and the Université de la Réunion through the federation Observatoire des Milieux Naturels et des Changements Globaux (OMNCG) of the Observatoire des Sciences de l'Univers de la Réunion (OSU-R). We are also grateful for the support offered by the Direction Générale de l'Armement (DGA). We finally thank our ULA pilot F. Toussaint.

\section{REFERENCES}

[1] Shang, X., and P. Chazette, 2014: Interest of a Full-Waveform Flown UV Lidar to Derive Forest Vertical Structures and Aboveground Carbon, Forests, 5(6), 1454-1480.

[2] Cuesta, J., P. Chazette, T. Allouis, P. H. Flamant, S. Durrieu, J. Sanak, P. Genau, D. Guyon, D. Loustau, and C. Flamant, 2010: Observing the Forest Canopy with a New UltraViolet Compact Airborne Lidar, Sensors, 10(8), 7386-7403.

[3] Tang, H., R. Dubayah, A. Swatantran, M. Hofton, S. Sheldon, D. B. Clark, and B. Blair, 2012: Retrieval of vertical LAI profiles over tropical rain forests using waveform lidar at $\mathrm{La}$ 
Selva, Costa Rica, Remote Sens. Environ., 124, 242-250.

[4] Lefsky, M. A., D. Harding, W. B. Cohen, G. Parker, and H. H. Shugart, 1999: Surface lidar remote sensing of basal area and biomass in deciduous forests of eastern Maryland, USA, Remote Sens. Environ., 67(1), 83-98.

[5] Boudreau, J., R. F. Nelson, H. A. Margolis, A. Beaudoin, L. Guindon, and D. S. Kimes, 2008: Regional aboveground forest biomass using airborne and spaceborne LiDAR in Québec, Remote Sens. Environ., 112(10), 3876-3890. 